\title{
EVALUATING THE SUSTAINABLE PERFORMANCE OF AN URBAN DISTRICT: MEASURED SCORE OR REFLEXIVE GOVERNANCE?
}

\author{
H. VANDEVYVERE \\ Department of Architecture, Urbanism and Planning, Katholieke Universiteit Leuven, Belgium.
}

\begin{abstract}
How to evaluate the sustainable performance of a complex urban system remains a much debated subject. In this sense, urban planning questions present many characteristics of the confusing decision contexts that arise with the management of sustainable development. Recent tools for assessing the sustainable performance of urban neighbourhoods have focussed on delivering a distinct score, obviously for reasons of benchmarking, communicative impact or marketing. However, these unequivocal scores partially hide or even confuse the complex quantitative-qualitative trade-offs that are needed to arrive at a judgement. This paper describes an alternative approach whereby quantitative measuring and qualitative assessments are combined. The resulting evaluation is primarily intended as a compass for reflexive governance, rather than as a sustainability label. The methodological basis for the instrument is derived from the theory of modal aspects, as formulated by the Dutch philosopher Herman Dooyeweerd. An indicator set and corresponding value functions are created, taking into account the expertise that can be found in many existing indicator systems. Performance thresholds, a new type of radar diagram and an argumentation are added to complete the assessment. Two instances of application are subsequently discussed. This allows observing the utility of the tool in a given context of both data and policy uncertainties. It appears that, even with many such uncertainties remaining, a useful strengths, weaknesses, opportunities and threats analysis can be performed. The necessity of properly addressing sustainable functioning from the very early planning stages is thereby confirmed.

Keywords: assessment, indicator system, multimodal system analysis, neighbourhood, radar diagram, sustainable urban development.
\end{abstract}

\section{INTRODUCTION}

Cities and urban networks have a major share in the environmental impact of today's societies through their concentration of population and economic activities (e.g. [1]). This impact results from typical functions of the urban-built environment and its infrastructures, on the one hand, and from a myriad of social and economic activities that come to be grafted onto these material infrastructures, on the other hand. Integrated urban sustainability, thus, results to be a complex goal to achieve.

In terms of the built environment, much attention has until now been dedicated to the sustainable functioning of individual buildings. However, it has become clear that aggregated sustainability benefits appear at the urban-scale level compared to optimizing single buildings and, more importantly, that ignoring sustainability factors at the urban scale will entail deficient overall system performance however good the individual building performances may be (e.g. [2-6].)

In this context, intervention at an urban fragment or district scale can be considered as the first step upwards from focusing on single buildings only. It is at this scale where the full complexity of interplay between factors, such as the planet, people and prosperity, occurs. In this way, the urban fragment establishes an essential link between the micro- and macro-functioning of urban structures.

An important requisite for adequate intervention at the (micro-)urban scale is to use appropriate evaluation tools. These instruments should permit one to understand, to assess and to guide sustainable urban development. For this goal, a specific indicator set will be selected, and subsequently valued through observation of the urban fragment under study. 
Evaluation does not come without methodological difficulties, however. This is particularly the case when undisputable quantitative assessments are intended for benchmarking or regulation goals. The complex trade-offs that characterize urban development projects complicate a straightforward translation of a stated sustainability aspect into a value or score, in particular because a wide diversity of quantitative as well as qualitative criteria must be combined into the final judgement. The quantitative data uncertainties, characteristic of many urban surveying processes, further add to the problem [7, 8]. Quantifying the unquantifiable may, therefore, be considered as the Achilles' heel of many evaluation tools. A good example of the difficulties involved in such process can be observed in recent instruments, such as LEED for Neighborhood Development [9] or BREEAM Communities [10]. Two instances illustrate the methodological difficulties encountered.

A first category of difficulties relates to the environmental impact assessments included in the instrument. The LEED tools are based on judgements made by LEED Committees, expert panels composed of stakeholders in the construction and real estate industries [11]. Criticism has been formulated regarding this expert valuation of LEED's environmental scores for buildings. Here the number of credits granted for a given measure or asset may not correspond to its real impact calculated through a life cycle assessment (LCA). Deviations can be substantial and rewarded measures may even instigate environmental burdens rather than benefits [12]. Similar criticism can be formulated for the neighbourhood tool. For example, a district heating or cooling network ([13]: 99) is not necessarily being rated according to the environmental optimum. Within LEED, a district heating or cooling network is always considered as beneficial, while single family housing and existing buildings may be excluded from the required calculations.

BREEAM valuations, although based on LCA input, equally depend on expert panels, in particular for weighting [14].

A second category of difficulties relates to qualitative judgements. For example, the credits for neighbourhood safety in BREEAM Communities depend on the fact that experts and technical guidance ('... or equivalent'), have been consulted ([10]: 187). This means that there is no judgement of safety as such, but a control of the processes put into operation to guarantee it. This tendency is illustrative of instruments that need to arrive at an unambiguous score, and therefore seek to find indisputable outcomes. So even if these instruments promote the idea of a sound and robust standard, a closer observation of their methodological basis indicates that many uncertainties and qualitative trade-offs remain embedded in the evaluation process.

Taking into account these fundamental issues, a more process-oriented scheme for sustainability evaluation has been developed as an alternative. Elements of such strategy can also be found with other acquainted assessment tools (e.g. [2]), but it is generally not the approach of commercial labels and official rating instruments (e.g. [15]). Resultantly, the alternative approach delivers a compass rather than a gauge and has particularly been thought of as an instrument for 'reflexive governance' [16]. At the same time, the alternative approach intends to deliver criteria that relate sufficiently to LCA, where appropriate. This is further discussed when considering the tension between determinative and normative requirements for sustainable development, under sections 2 and 4.

Three elements provide the basis for the development of the proposed method. First, referring to research in political sciences, indicators will be primarily conceived as 'boundary institutions' that facilitate information exchange between scientists, decision makers and stakeholders [17]. Second, a new form of radar diagram is developed for better visualization of complex valuations, minimizing perception bias while maximizing useful information content. Third, performance thresholds and qualitative accounting are added as indispensible components of the judgement palette. Qualitative judgements are used both in indicator valuations and for the overall assessment. Performance thresholds must guarantee that essential conditions for sustainable functioning are fulfilled, regardless of the obtained overall score. 


\section{METHODOLOGICAL BASIS FOR THE DEVELOPMENT OF THE INSTRUMENT}

Since the emergence of the urban sustainability theme, many hundreds of assessment instruments have been developed [18]. Survey studies indicate a tense relationship emerging between the "hard" certainties of the bio-physical sciences and the more uncertain and risky sphere of economic and social relations ([19]: 2). In addition, the multi-aspect relationships between the present environmental problems on the one hand and their direct or indirect socio-economic impacts on the other hand add to the many uncertainties about the validity of indicator systems and assessment methods for sustainability evaluation. These tensions are reflected within the scientific community. Researchers in the human sciences tend to emphasize the 'social construct' side of the problem, whereas their peers in the exact sciences usually point to the bare realities of climate change and resource extinction as a primary basis for analysis and subsequent intervention. This sometimes leads to sharp and long-lasting controversies, as can be observed in the field of architectural theory [20-24]. Views from within distinct disciplinary 'silo's' thereby hamper a truly interdisciplinary analysis of the sustainability question at hand. This problem is closely related to the validity question in interdisciplinary research, where no 'meta-theory' is available for proving the correctness of cross-border, overarching assessment methodologies ([25, 26]: 188-190). As a result, few methods aiming at integrated sustainability evaluation risk digging deep into the validity question.

For the present research, this confusing context has prompted a return to the philosophy of science. In this case, a literature review lead to a research track initiated by Donald de Raadt and Andrew Basden in system sciences [27, 28], which was subsequently picked up by Peter Brandon and Patrizia Lombardi in the field of sustainable urban development [29, 30, 8, 31]. The basis for this work are the writings of Herman Dooyeweerd, whose research in the first half of the last century was primarily concerned with philosophy of law. Nevertheless, Dooyeweerd underpinned this work by purely philosophical research, which led to the formulation of the theory of the 'modal spheres' $[32,33]$. This framework has been adopted for the present research because of its combined profoundness and operability, compared to other approaches [26,34]. It also presents a method of coping with the validity problem by situating the research questions in a wider landscape of knowledge theory.

In particular, the conflict between quantitative and qualitative border conditions for sustainable development can thus be interpreted in terms of a tension between the 'determinative' conditions for environmental sustainability and the 'normative' conditions that define the sustainability of society as a whole $[31,26]$.

The methodological basis for arriving at this conclusion is briefly reviewed below.

In summary, Dooyeweerd's theory states that we can know reality through its aspectual manifestations. These aspects or modalities concern 15 distinct spheres with a stated order: the numerical, the spatial, the kinetic, the physical, the biological, the sensitive-psychical, the analytical-logical, the historical-cultural, the linguistic-communicative, the social, the economic, the aesthetic, the jural, the ethical and the credal 'law-spheres' ([32]: 3-4).

The main interest of multimodal system analysis lays in its derived system properties and how these refer to sustainability assessments.

Important system properties are as follows [26, 33, 27]:

- the relative autonomy or sovereignty of each modal aspect (law sphere) requires that it receives an explicit address: it is autonomously knowledgeable;

- lower order aspects make up the foundation (substrate) for higher order aspects (e.g. biological life is not possible without physical matter);

- thereby the character of the spheres evolves from determinative (based on the laws of mathematics and physics) to normative (based on human conventions); 
- 'anticipations' (forward influences) and 'retrocipations' (backward links) occur in the modal chain of aspects; and

- a lower modality can function as an idiom or metaphor for a higher modality (e.g. social reality can be metaphorically described by statistics within the numerical modality). However, an idiom cannot fully characterize the modality it represents, and the descriptive difficulties increase with the distance between the two law spheres (e.g. establishing the value of a human life by means of an insurance amount opposes the ethic value to the economic appreciation; the latter is additionally expressed as a numeric value (price) and so the value of a human life is further metaphorically reduced). In other words, this literally points to problems of reductionism.

When projecting these insights onto problems of sustainable development, we may propose the following conclusions:

- The range of aspects, for assessing sustainable development, should be considered until they reach the ethical sphere. As can be understood from acknowledged definitions, such as the Brundtland description, sustainable development indeed depends on an ethic engagement at the normative end of the modal chain, namely not compromising the ability of future generations to meet their needs ([35]: Chapter 2, Article 1). From there, sustainability conditions retrocipate into the lower order aspects, such as limited $\mathrm{CO}_{2}$-emissions in the physical sphere. This is similar to the concept of human rights, where the respective ethic norm retrocipates into aspects such as the free expression of opinion or the right to proper housing and education;

- By consequence the concept of sustainability may be regarded as normative with determinative foundations.

- A multidisciplinary framework is needed for the proper treatment of all concerned law spheres, and for reasons of sphere sovereignty all aspects, including ethics, should receive an explicit, autonomous address;

- Within the same perspective there can be no social or economic sustainability without environmental sustainability for reasons of retrocipative foundation. This implies that sustainable development is integrated, or it is not.

- Determinative (quantitative) idioms present the risk of reductionism because they cannot fully qualify the higher order normative aspects. In a similar way, specific scientific disciplines deliver constitutive yet partial assessments of integrated sustainable development. Within the same logic, a danger arises when sustainable development is too narrowly considered from a strictly environmental, social or economic standpoint.

Although these statements may seem bold at first sight, it can be demonstrated that multimodal system analysis facilitates a deepened interpretation of current sustainability debates by providing substantive theoretical insights, while at the same time delivering a high potential of straightforward application in real-world situations. As such, Dooyeweerd's philosophy has, for example, been used for ecological farm management [36].

\section{PRECONDITIONS FOR THE ASSESSMENT INSTRUMENT}

When setting up the instrument, the methodological basis of applying multimodal system theory has been complemented with a series of practical considerations. From both a literature review and field inquiries, a set of preconditions for the assessment instrument has thus been determined. These are, summarizing ([26]: 196-197): 
- To provide a comprehensive and transparent way of assessing sustainability so that professionals can go through the evaluation process with a larger group of participating stakeholders $[37,8]$. Comprehensiveness is further enhanced by limiting the number of indicators that must be considered simultaneously.

- To consider sustainability components through indicators that are effective at the micro-urbanscale level. Efficiency can be gained by integrating input from other evaluations carried out at the same time, for example: environmental impact assessments (EIAs), energy performance regulation (EPR) calculations, building simulations, compulsory water management checks, LCAs and life cycle costing (LCC);

- To focus on results rather than on the means to achieve these results;

- To provide a strategy to deal with uncertainties;

- To be flexible enough to allow adaptation to the unique context of a particular project;

- While not remaining so undefined or elastic so that individual stakeholders can divert the evaluation process towards their sectorial concerns, thus harming the common interest or the overall sustainability targets (e.g. [7]).

By evaluating qualitative results, rather than the means to achieve these results, the method adopts a different approach compared to pure rating systems. For example, social safety or spatial quality will be assessed 'in se' and will not be valued procedurally, for example, by controlling if a crime prevention expert has been consulted or if a spatial quality surveyor has been assigned. The latter type of approach is characteristic of established rating tools, such as BREEAM Communities [10] (see above) or Duurzaamheidsmeter Gent (a tool developed by the city of Ghent, which is gaining wider interest for application in Belgium) [38].

Even if qualitative judging may, from a theoretical point of view, be considered as intangible by definition, it should be noted that it does occur as a common practice. Architectural or urban planning competitions provide us with an excellent instance. The qualitative choices made by competition juries are accepted even if the economic consequences for the participants are far-reaching.

\section{INDICATOR SYSTEM AND COMPOSITE TOOL}

This section explains the components of the instrument in terms of indicators, scores and weighting factors, exclusion thresholds, radar diagram and argumentation.

\subsection{Indicators}

A set of indicators makes up the basis of the system. As mentioned in the introduction, these indicators are thought of as boundary elements that facilitate knowledge transfer between concerned parties. The accessibility of the evaluation results to field actors and stakeholders is increased by using a concise set of main indicators divided into four categories that are easy to grasp. Main indicators can be composed of up to four sub-indicators. Two major inputs guide the selection of these indicators: a survey of existing indicator systems, on the one hand, and multimodal control for completeness of the set, on the other hand. This approach marries the need for a theoretical basis with the pragmatic absorption of the expertise embedded in the indicator systems that have been analysed in the literature review [26].

With the aim of constructing a working basis, several types of existing indicator system have first been screened for valuable input. The analysed systems can be distinguished as belonging to four major spheres: academic and research-oriented; market-based; mixed and 'ad hoc' or project-based. Mixed instruments refer to tools that result from a collaboration between research institutes, 
consultancies and/or (local) authorities. In total, 19 indicator systems have been analysed this way, among which LEED for Neighborhood Development, BREEAM Communities, the Hammarby Sjöstad Model [39] and BedZED's 21 Steps Chart [3], to name a few of the better-known examples.

The resulting pragmatic set of possible indicators has subsequently been reworked and controlled for modal completeness. Hereby it can be argued that a selection of nine aspects should be directly accounted of when analysing sustainable performance ([26]: 107-111; [34]). In fact, when composing the corresponding indicator system, Dooyeweerd's ontological description of reality should be translated towards a framework for the operational description of reality, in this case sustainable functioning. This can be achieved by first categorizing Dooyeweerd's aspects into groups, as respectively:

- three pre-determinative aspects (the immaterial basis of the numerical, the spatial and the kinetic spheres);

- two determinative aspects describing the material world (the physical and the biological sphere ruled by the deterministic rules of the natural sciences);

- two pre-normative aspects anticipating the human normative world (the sensitive-psychical and the analytical-logical spheres, that is, the human capacities of feeling and thinking/knowing);

- seven normative aspects describing human society in terms of social construct (the historicalcultural, the linguistic-communicative, the social, the economic, the aesthetic, the jural and the ethical spheres);

- one 'un-conventional' aspect (the credal) which is not considered in sustainability analysis because the spiritual scope is not included in accepted sustainability definitions. It does however retrocipate into these spheres, and it is also being anticipated, in particular, by ethics.

For the intended operational analysis, the pre-determinative and pre-normative spheres appear to describe the foundations of the determinative and normative spheres, rather than directly pointing to the very operational characteristics of the manifest world. As such, they are not considered as direct control parameters for a sustainability indicator system. Furthermore, and as argued higher, the system boundaries of accepted sustainability definitions reach until the ethical domain but do not mandatorily include spiritual motives. This means that the credal sphere is 'optional', which in Dooyeweerd's terms means that its anticipative and retrocipative qualities are recognized while the sphere itself is not strictly being included.

Two types of knowledge input may thus be distinguished: nine directly concerned aspects as mentioned above, to be modally represented and five 'feeders' (e.g. statistics in the numerical sphere to analyse social or economic phenomena, see also above under section 2 concerning the use of an idiom). Figure 1 schematically represents the resulting process and its output. As a result, the indicators cover the whole range from determinative 'planet' over basic normative 'people' and complementary normative 'prosperity' to higher normative aspects 'process, policy'.

Complementary input was obtained from an expert panel (see also section 4.2). The indicators are grouped in four categories that correspond to the classical 3P division 'planet, people, prosperity', completed with a category that controls process quality and integrity. This may be compared with ISO 14031's distinction between 'operational performance indicators' (3P categories) and 'management performance indicators' (steering category) [40].

An observation should be made about the interdependency of the indicators. It appears that a workable set is always composed of indicators that influence each other, and are therefore not strictly independent. For example, the sustainability of the transport system analysed under mobility influences spatial quality and physical quality of life (absence of harmful emissions and nuisance) and, thus, indirectly many other environmental and social aspects. A similar reflection can be made about 


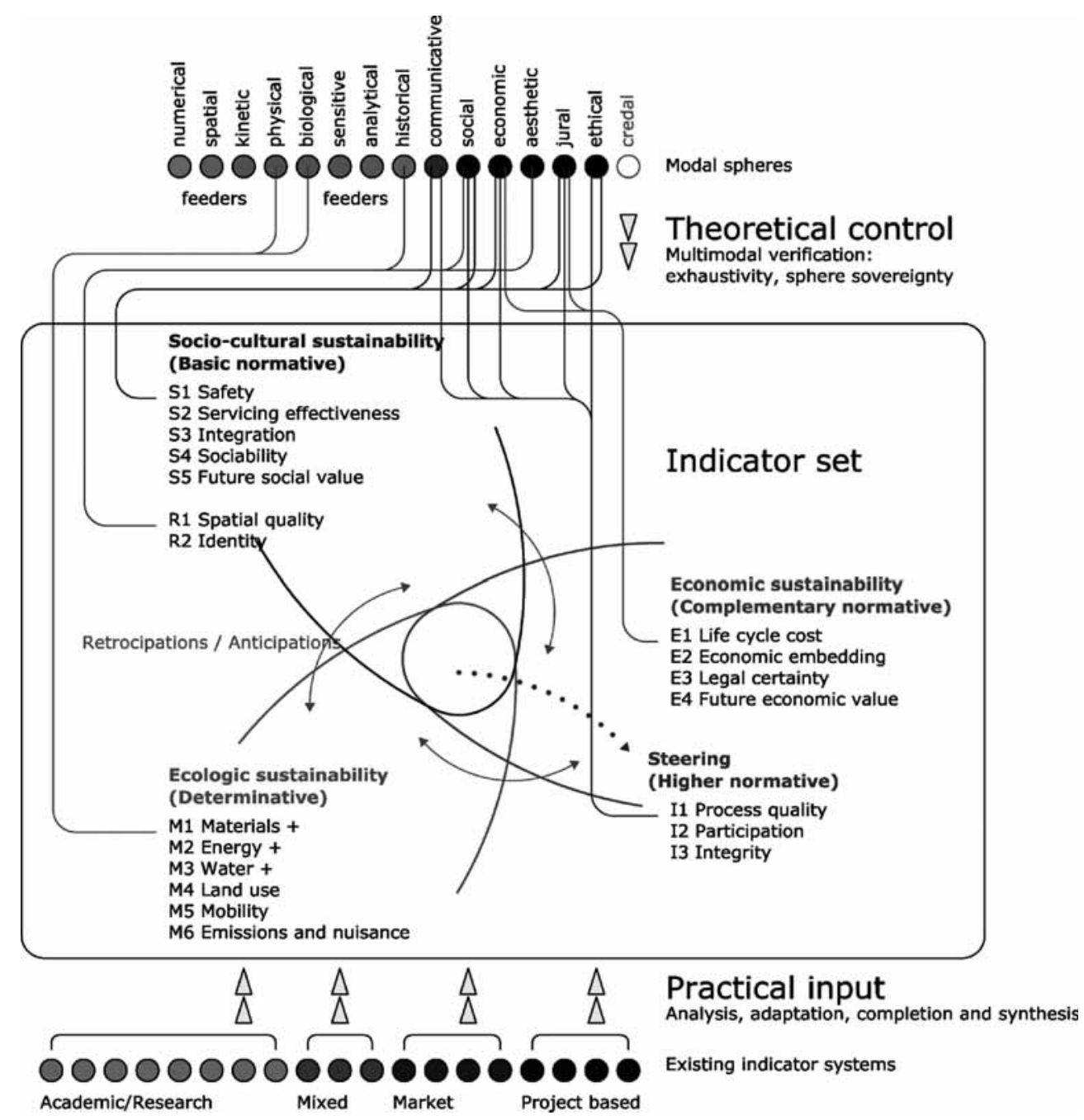

Figure 1: Inference diagram for the composition of the indicator system, based on a Planet, People, Prosperity (3P) division with a steering category added for theoretical and aspectual completeness. Five 'feeder' spheres do not directly relate to the intended indicator selection but indirectly support it; the credal sphere is not considered on the basis of the theoretical analysis of accepted sustainability definitions.

economic behaviour viewed as a social construct, or about any other links between modal aspects. This phenomenon is accounted for in multimodal system analysis, in terms of the inevitable anticipations and retrocipations that exist between the modal spheres. In fact, the only independent variable for our analysis appears to be the integrated sustainability itself. However, when assigning effects to particular indicators, it remains important to avoid double-counting. For example, energy use for transport will be considered under the indicator 'energy' and so not again under the indicator 'mobility'.

Sub-indicators make up the technical layer for the assessment. As an example, the sub-indicators for energy consumption during the use phase, and for spatial quality, are explained below. 
Energy use is assessed by considering:

- Fossil energy consumption in buildings and infrastructures during their exploitation, expressed as surface-averaged $\mathrm{kWh}$ primary, fossil $/ \mathrm{m}^{2}$, year or as $\mathrm{kWh}$ primary, fossil $/$ person, year;

- Environmental quality of the building and infrastructure energy use expressed as proportionally averaged Ecopoints/kWh;

- Fossil energy consumption for transport of inhabitants and users, expressed as $\mathrm{kWh}_{\text {primary, fossil }}$ / person, year.

Energy embedded in building and infrastructure materials is included in the materials indicator through an LCA score.

The energy assessment is therefore not a pure LCA analysis but reflects a series of actual priorities as follows:

- to reduce the fossil energy consumption of buildings and urban infrastructures;

- subsequently, to fill in the remaining energy demand as environmentally friendly as possible; and

- to add the location impact of settlements on transport energy in order to complete the energy consumption figure of the urban fragment.

This approach is similar to the principles of the 'trias energetica' [41]. Moreover, the subdivision allows one to handle certain problems of data collection and modelling: at the neighbourhood scale, it is very difficult to assess mobility effects, whereas estimating intra-building energy figures is more feasible. The sub-indicators allow, thus, giving relief to the information in terms of uncertainty degrees. Of course, this relief is lost at the aggregation level of the main indicators, but the processed information remains available for in-depth analysis.

In contrast with the quantitative assessment of energy use, spatial quality is judged in exclusively qualitative terms. The valuation is structured by a non-exhaustive series of aspects to be judged, as follows:

- gradations of public and private character, transitions between these spheres, buffer areas, and corresponding changes of scale;

- articulation of the different programmatic elements with respect to each other; in particular, the relation between buildings and infrastructures and the possible barrier effects of the latter;

- meaningful integration of green structures and green-blue networks into the urban landscape;

- visual landscape quality and scenic beauty;

- legibility and permeability of the urban tissue;

- integration of different architectural concepts in a given setting or master plan; and the articulation and integration of existing patrimony herein; and

- authenticity and architectural quality of individual buildings.

The final score is normative but could be numerically composed by assigning symbolic ratings to each of the individual aspects and subsequently weighting them. In the present state of the instrument, such partial scoring and weighting has not been provided for, for spatial quality. Whether or not this is done depends on how far users want to instrumentalize the evaluation. This problem is very similar to the challenges of judgement formulation in, for example, architectural competitions.

Mixed sets of sub-indicators are used as well. This means they include quantitative (determinative) and qualitative (normative) aspects. Symbolic rating and weighting allow aggregation into the corresponding main indicator score. 


\subsection{Scores and weighting factors}

All indicators and sub-indicators are scored on a scale from 0 to 10 , independent of their quantitative/qualitative character. Value functions may be mathematical (e.g. linear interpolation between scores corresponding to a minimum (score 0 ) and maximum (score 10) performance) or symbolic (assigning points corresponding to a structured qualitative judgement). In general, the critical factor was found to be the right choice of 'worst' and 'best' performance for a given criterion. This holds in particular for determinative valuations. Here, 'worst performance' generally corresponds to the state of affairs typical of the commonly used reference year 1990, while 'best performance' is put at an ambitious limit corresponding to closed environmental loops.

To arrive at an overall score, sub-indicators and indicators are aggregated by means of a weighted sum.

For aggregating the main indicators, a set of weighting factors had been established by an expert panel. The consulted panel included 20 professionals from academia, government functions and the private sector (designers, consultants, project developers, and so on). The experts were selected for their authority and familiarity with problems of sustainable urban development in the Belgian region of Flanders, the context of the research. The reference situation to be weighted was an urban development with a dominantly residential programme. The experts were asked to weight each individual indicator, and then to check if the resulting partially summed weight for each category corresponded to the importance they would assign to that category as a whole. If this was not the case, weights had to be redistributed until the categories received the proper aggregated weighting.

Apart from assigning weighting factors, the experts were also asked for intrinsic feedback about the indicator system (cf. section 4.1). One outcome of this consultation was that adding the steering category with its process indicators was judged as useful by the majority, if not completely necessary.

Table 1 resumes the averaged weightings obtained from 17 respondents.

Table 1: Rounded indicator weights and corresponding standard deviations (SD).

\begin{tabular}{lrrlrr}
\hline Category/indicator & $\%$ & SD & \multicolumn{1}{c}{ Category/indicator } & $\%$ & SD \\
\hline Environmental aspects & $\mathbf{3 7 . 5}$ & & Socio-cultural aspects & $\mathbf{2 5 . 5}$ & \\
Materials+ & 5.0 & 1.95 & Safety & 3.0 & 1.14 \\
Energy+ & 8.5 & 5.47 & Servicing effectiveness & 4.0 & 1.88 \\
Water+ & 5.5 & 1.75 & Integration & 3.5 & 1.66 \\
Land use & 7.0 & 3.86 & Sociability & 3.5 & 1.46 \\
Mobility & 7.0 & 2.48 & Future social value & 3.5 & 1.89 \\
Emissions and nuisance & 4.5 & 1.55 & Spatial quality & 4.5 & 1.53 \\
& & & Identity & 3.5 & 1.32 \\
Economic aspects & $\mathbf{1 8 . 5}$ & & Process aspects & $\mathbf{1 8 . 5}$ & \\
Life cycle cost & 5.0 & 2.17 & Process quality & 6.5 & 2.61 \\
Economic embedding & 4.5 & 1.65 & Participation & 6.5 & 2.98 \\
Legal certainty & 4.5 & 2.25 & Integrity & 5.5 & 2.73 \\
Future economic value & 4.5 & 1.96 & & & \\
\hline
\end{tabular}

The standard deviations are fairly proportional to the weight values. 
As a critique, the averaged opinion of the group of experts could be judged as being 'grey' or levelled off. On the other hand, the procedure assures a higher degree of robustness while some tendencies still remain clear, in particular, the dominance of the environmental category.

Particular contexts can justify a different weighting set, as far as arguments are brought in for doing so. For example, an urban development around a railway station may require increased attention for mobility, nuisance prevention and servicing effectiveness, at the cost of other factors. The assessor in charge of the evaluation (see below in section 4.5) controls this contextual adaptation in consultation with the different stakeholders. The above weight factors then serve as a benchmark.

Weighting factors for sub-indicators have not yet been assigned on the basis of an expert consultation but are currently derived from arguable working hypotheses.

\subsection{Exclusion thresholds}

To avoid compensation effects whereby a satisfactory overall score is obtained while severely underperforming on one or more indicators, a set of minimum requirements for sustainable functioning has been defined. A development cannot be considered sustainable if one of the following requirements is not met:

- an appropriate location (expert judgement);

- space heating and cooling demand in new buildings under $50 \mathrm{kWh}$ primary $/ \mathrm{m}^{2}$, year (European moderate climate);

- an acceptable service level of public transport (calculated sub-indicator score of minimum 5/10);

- sustainability investments with a simple pay-back time of 5 years are automatically carried out (compared to common practice on basis of legal minimum standards).

\subsection{Radar diagram}

A new type of radar diagram representing the indicator scores has been developed, with the aim of reducing perception biases that are characteristic of common radar types, as represented in Fig. 2.

The biases mainly originate from two effects: a strong angular and surface distortion near the centre of the circular representation on the one hand, and a different shape of score-connecting lines and figures, depending on the sequence in which the scores are represented, on the other hand.

The solution for this problem consists of keeping all graphical elements away from the circle centre.

For maximum legibility of the aggregated score, the new radar diagram is set up as follows (see Fig. 3):

- the surface of a score block is proportional to the indicator's weight factor in the overall score;

- the colour of a score block represents the actual indicator score (going from red for 0, over orange for 4.1-5, to dark green for 9.1-10);

- the actual score is annotated in the score block;

- the four indicator categories are marked by a graphical segmentation.

\subsection{Argumentation}

As stated in the introduction, the present evaluation is intended to serve as a compass that facilitates an approach of reflexive governance, rather than as a gauge for awarding labels. This implies that 

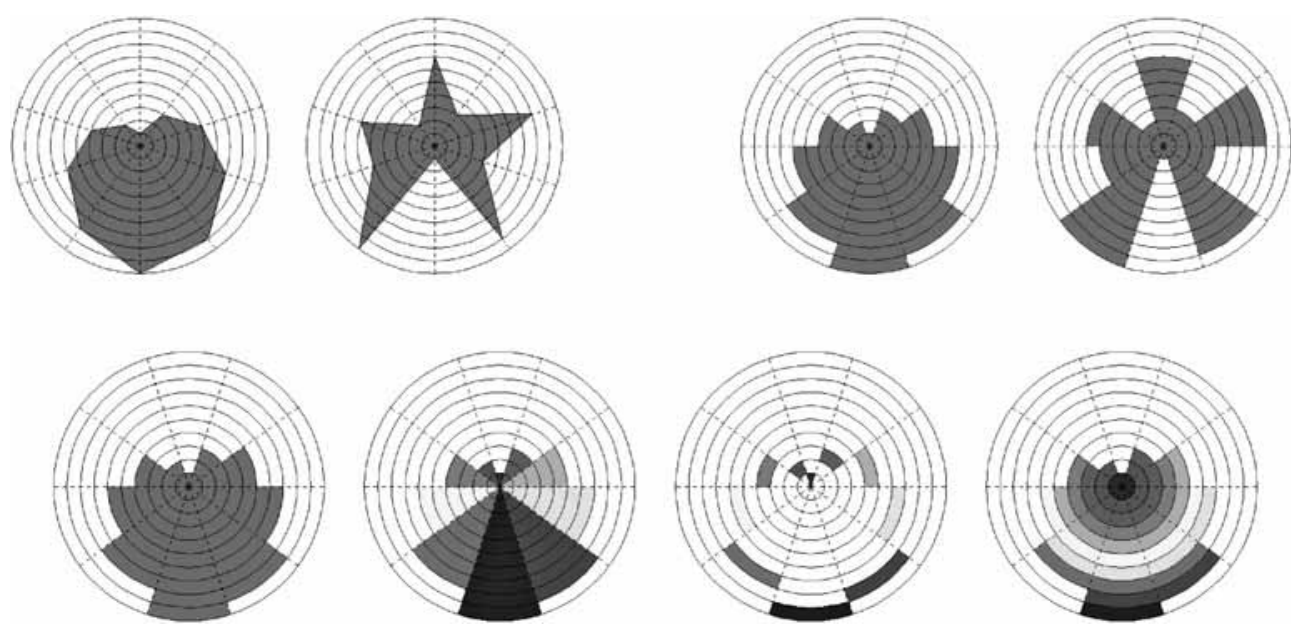

Figure 2: Typical radar diagrams representing the same score group (a series of scores ranging from 1 to 10). A perception bias originates from angular and surface distortions, as well as from connecting lines that display another figure depending on the order in which the scores succeed each other (note: original colours appear as shades of grey in this figure).

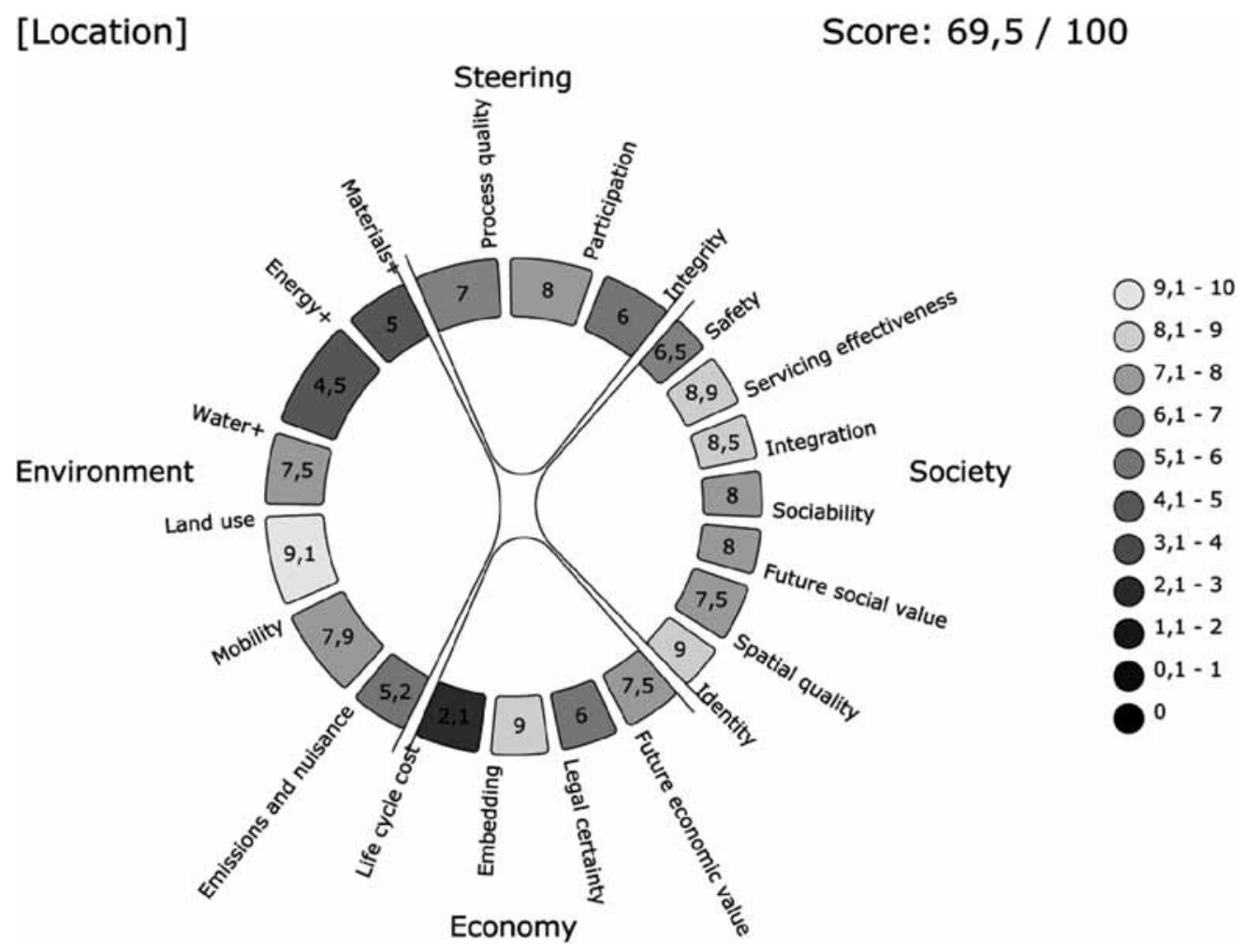

Figure 3: Radar diagram. Colour tones from red over orange to green have been replaced by shades of grey $($ black $=0$; light grey $=10)$. 
actors and stakeholders acquire a deeper insight into the sustainable performance of an urban project and do not solely focus on end scores. Eventual barriers and shortcomings that hinder sustainable development need to be unearthed and understood to enable targeted remediation.

Providing a consolidated integrity check is of particular importance. Actors and stakeholders have to verify if the sustainability claims they forward stand interrogation to provide holistic sustainable development. If this is not the case, the sectorial agendas of concerned parties may need adjustment.

Because of its debatable nature, the entire evaluation process will preferably be managed by an independent assessor. This 'quality control' partner assures that quantifiable inputs are correctly handled, qualitative judgements properly balanced and the aspirations of the different actors and stakeholders considered by referring to a solid definition of sustainable development.

Intrinsic quality discussions hereby present not only the obvious risk of conflicting valuations but also the opportunity of reaching the core issues of sustainable development. Such strategy coincides with the goal of a result-oriented instrument, rather than a means-oriented one. It should also help to overcome the problems of trying to quantify the unquantifiable.

\section{DISCUSSION OF TWO CASE STUDIES}

In its present state, the instrument has been tested in three case studies ([26]: 261-404). The selected cases are an urban Brownfield redevelopment (Antwerp docklands), a peri-urban infill project (Mechelen) and a Greenfield development at the city fringe (Sint-Niklaas), all in the northern part of Belgium.

Two cases are briefly discussed in terms of indicator scores and exclusion thresholds. Both were in the planning phase at the time of assessment. For convenience, the Greenfield project is left out as it presents the lesser degree of complexity among the three.

\subsection{Cadix dockland reconversion project, Antwerp}

The project site is an artificial semi-island, Cadix, just north of the historic centre of Antwerp (Fig. 4). It was part of Antwerp's 19th century harbour infrastructure and actually consists of a
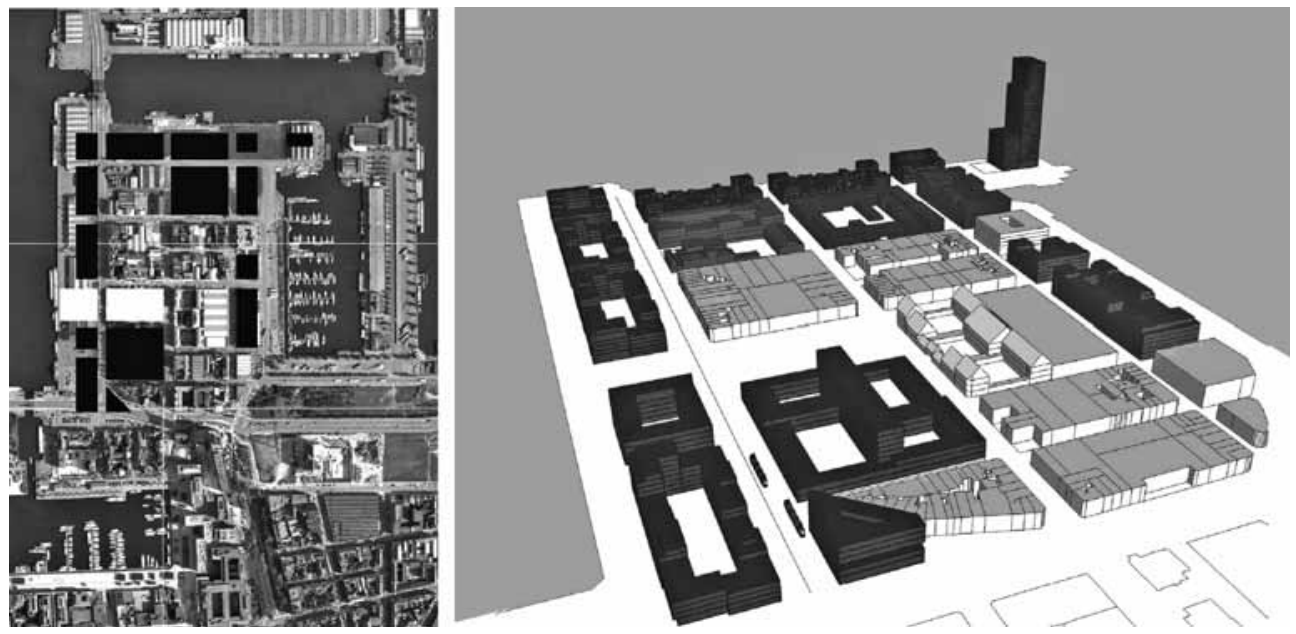

Figure 4: Aerial photograph and perspective of Cadix semi-island with the projected new developments indicated in dark shades. Images on basis of Google Maps and [42]. 


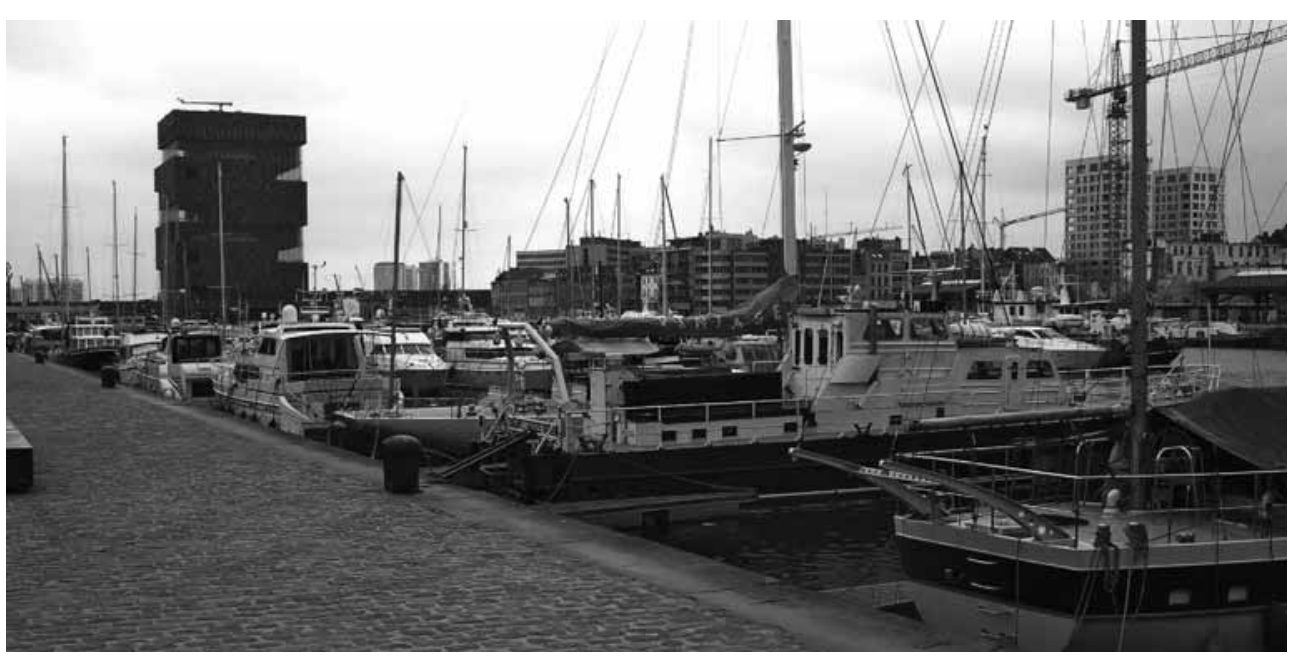

Figure 5: New marina in the historic Oude Dokken, south of Cadix; in the background the MAS museum situated on the new cultural axis.

maritime industrial fringe on the docksides, surrounding a core area with older warehouses and residential buildings. It borders two other historic districts of the harbour, Oude Dokken and Montevideo, which together with Cadix constitute the first phase of a larger urban renewal project. Oude Dokken and Montevideo will include a new Cultural Axis, comprising the recently opened MAS (Museum at the Stream) as its landmark (Fig. 5). The area is dotted with remarkable historic buildings related to the maritime history of Antwerp. One such example is the departure hall of the former Red Star Line located in Montevideo, now under restoration to house an emigration museum similar to New York's Ellis Island.

It was decided to relocate the last industrial activities remaining at Cadix, so that the entire semiisland could become part of the urban renewal programme. As a result, the Cadix project consists of three major components: the refurbishment of the public domain including important new public transport facilities; newbuild for a mixed programme in the vacant fringe; and renovation efforts in the old core. The envisaged functional mix consists of $75 \%$ housing, maximum $21 \%$ offices and commerce and minimum 4\% (public) services.

The redevelopment of the industrial fringe is organized by means of public tenders per street block, whereby developers may obtain a variable subsidy depending on the energy-standard realized for the new buildings.

\subsection{Sustainability assessment for Cadix}

The scores corresponding to the project status as of early 2010 are briefly discussed in the following paragraphs. It should be noted that the contracting-out of new constructions had already started at that time.

\subsubsection{Environment}

The project site is ideally located at walking distance of Antwerp's historic centre and will be connected with the city through an effective network of public transport lines, biking lanes and pedestrian 
connections. As an urban Brownfield conversion project, it is exemplary of sustainable land use. However, less attention has been paid to energy consumption, water and building materials usage. City authorities have preferred to stimulate the construction of low-energy buildings through a system of limited subsidies, while as owners of the construction grounds, they could simply impose an ambitious (very) low-energy standard. A limited focus on building material cycles coincides with such general tendencies in the construction sector. A similar conclusion holds for the water cycle.

Meanwhile, the environmental weaknesses of the renewal scheme have been detected by the project initiators and are being worked on. As an example, the city is studying the possibilities of several district heating scenarios to deliver a sustainable alternative for classical heating and cooling installations. Nevertheless, this correction strategy does not come without difficulties: it is much more effective to consider such options at the early programming stages for reasons of optimum integration and maximum cost efficiency.

\subsubsection{Socio-cultural aspects}

The renewal scheme performs very well in socio-cultural terms. This is due to acceptable and likely improving social safety and a wide range of services at appropriate distances. Other well performing schemes are the integrative urban housing programme including social and affordable housing projects, targeted actions for social cohesion, ample attention for spatial quality and a strong identity derived both from the maritime past and the new cultural and maritime infrastructures.

\subsubsection{Economic aspects}

Economic embedding and flexibility show promise. Strong points are the mixed programme and the consultation of economic actors through collaboration with the regional chamber of commerce and industry. However, legal certainty suffers from several difficulties: a conflict with the port authorities over decontamination costs; a disputed interpretation of specific housing norms and planning prescriptions; and legal obstacles for alternative development trajectories. The life cycle cost strategy of the building construction interventions is poor. This is caused by weak investment incentives for environmental performance and so the low LCC score can be observed to cluster with the poor scores of the environmental indicators for energy and materials.

\subsubsection{Process aspects}

The city of Antwerp has established a strong practice of project management and participation strategies, which reflects in the respective indicators. However, efforts for realizing fully integrated sustainability have been less effective. In this context, two elements are significant. First, the environmental aspects that were initially overlooked start to receive more attention. But this happens at the cost of additional difficulties, as mentioned above. Second, the liveability of the urban renewal project is threatened by a new highway connection, including a suspended bridge, directly north of the urban renovation zone. Although the latter project remains contested and its realization undecided, the city has thus failed to integrate sustainability goals coherently throughout the different urban-scale levels, particularly from the outset of both the highway and the urban renewal projects.

\subsubsection{Overall result and radar diagram}

Cadix has a very high sustainability potential. This potential is largely being realized in the social, economic and project management categories. However, as local authorities have failed to impose strong environmental standards from the early planning phases, certain environmental scores remain mediocre to bad. The resulting indicator scores are visualized in the radar diagram of Fig. 6. 


\section{Cadixwijk, Antwerpen $\quad$ Voorlopige score: 70 / 100}

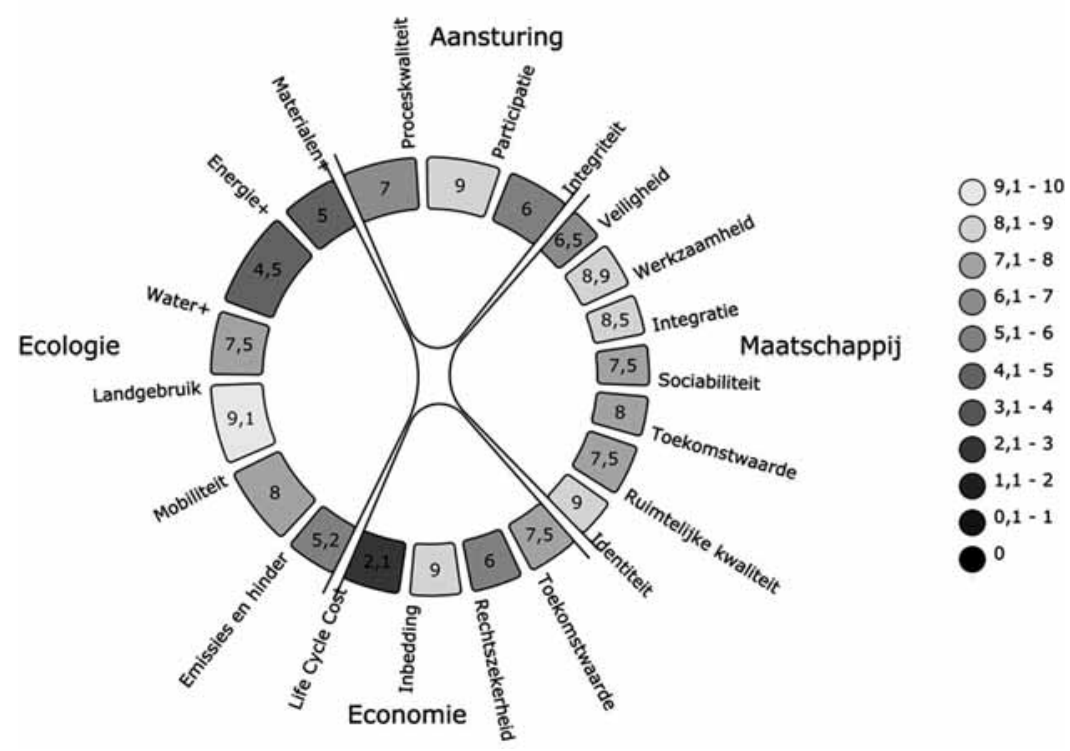

Figure 6: Radar diagram for the Cadix urban renewal project (English terminology corresponding to the indicator names can be found in Fig. 3).

\subsubsection{Exclusion criteria}

The threshold for newbuild energy consumption is not reached and so the label 'sustainable' cannot be assigned. In the light of Cadix's high sustainability potential, this is a dramatically missed opportunity.

\subsection{Spreeuwenhoek peri-urban infill project, Mechelen}

The neighbourhood of Spreeuwenhoek is located $3 \mathrm{~km}$ south-east from Mechelen's historic city centre. The area consists of a linear urban development along the national road N26, and a parallel fringe of agricultural land dotted with pockets of housing and woodland. The main characteristic of the area is that it is enclosed between two infrastructure systems acting as hard borders: a canal to the south-west and the national road plus a railway bundle to the north-east. Towards the city centre in the north-west, the area borders an enterprise zone linked to the railway infrastructures. On the opposite side, it is adjacent to a zoological park.

The area is typical of much of Flanders' territory, in the sense that it may be characterized as 'nevelstad' or 'nebulous city' for its undistinguished peripheral mix of urban and rural functions (Fig. 7). A considerable problem is the saturation of the N26 as an access road to and from Mechelen. Parts of the area are also prone to flooding and the permeability of the soil is low.

In 2002, Spreeuwenhoek was designated as one of the urban extension areas for Mechelen, with a target of around 700 new dwellings. Due to political circumstances, however, plans have changed since. As of 2010, a classical allotment was foreseen with no more than 300 houses, many of them planned as detached single-family homes (Fig. 8). 

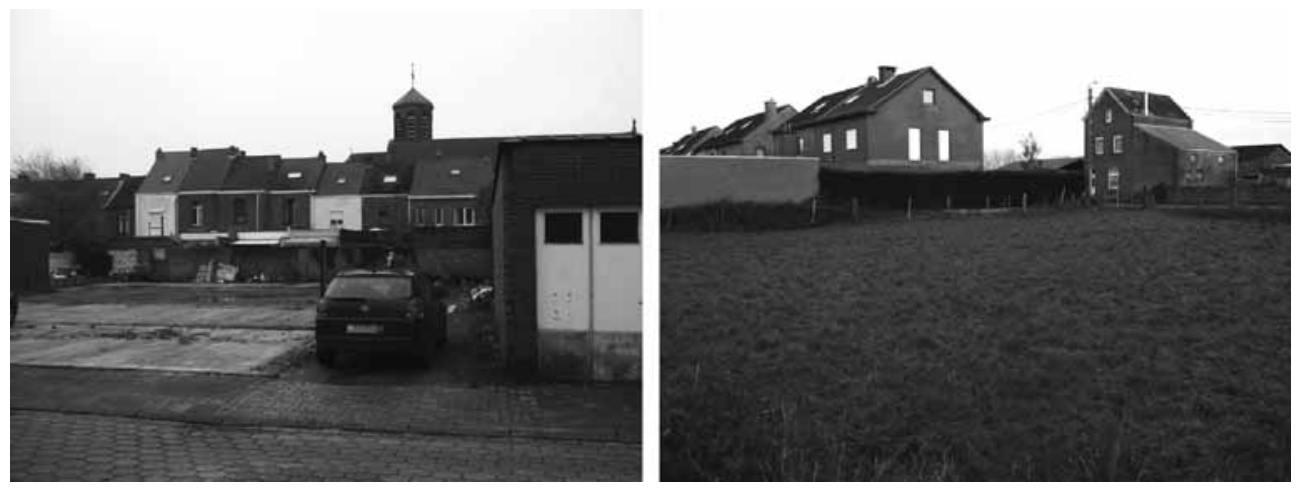

Figure 7: Existing neighbourhood (left) and dispersed housing in the agricultural fringe (right).

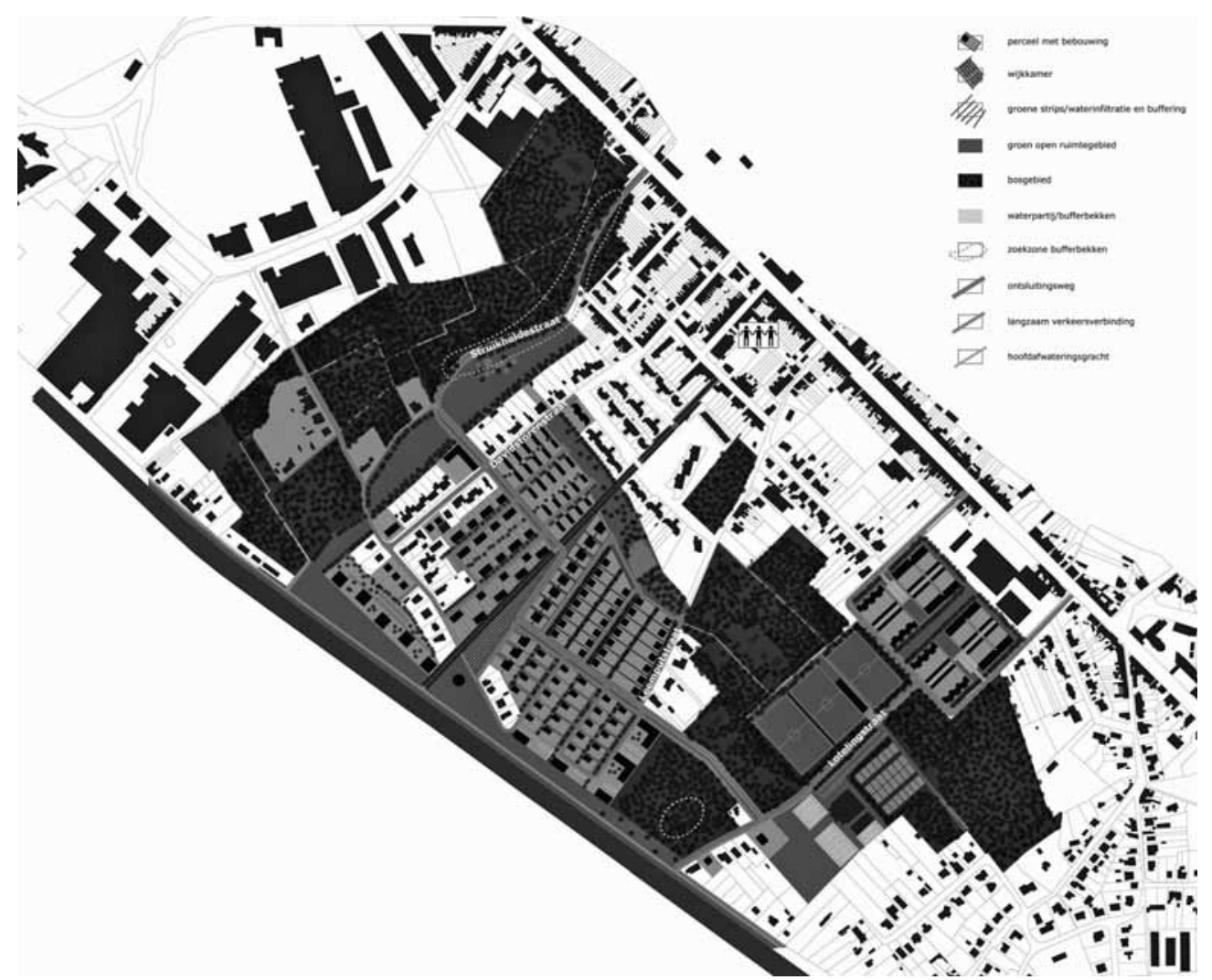

Figure 8: Development plan for Spreeuwenhoek, status 2009. Minimal changes occur in 2010. The canal Mechelen-Leuven is situated to the south-west of the new allotment; the existing neighbourhood along the N26 access road to Mechelen is situated to the north-east. Across this road lies the railway bundle (area left white on the plan). Image source: Technum/City of Mechelen. 


\subsection{Sustainability assessment for Spreeuwenhoek}

It should be no surprise that the standard allotment, as planned in 2010, performs badly on all but a few sustainability indicators. The main flaws and weaknesses of this design are summarized below:

\subsubsection{Environment}

As the plans do not impose any environmental performance above legal building prescriptions and standard practices, the scores are mediocre to bad. Planning prescriptions like 'use of sustainable materials' come without any specification, and so are 'de facto' void.

In terms of land use, and considering the proximity of the urban centre, the projected building density is far too low. The average is 15 dwellings/ha.

A new access road to the allotment is planned. This crosses the most valuable piece of woodland in the area.

The only good score to be noted is the absence of emissions and nuisances. In particular, the existing buildings along the $\mathrm{N} 26$ act as a noise barrier for the newbuild.

\subsubsection{Socio-cultural aspects}

Hardly any services are provided on-site, and the allotment is designed in separation from the existing neighbourhood. Symptomatic of this segregation is the new access road through the woodlands, which must provide the inhabitants with their own entry of sufficient prestige. No urban renovation programme is proposed for the existing neighbourhood, its infrastructure and its services, although this is hardly needed. New social housing is provided according to the norms, but it is grouped at the border of the development area.

\subsubsection{Economic aspects}

For its quite exclusively residential character, the development plan performs badly on economic embedding. Similar to Cadix, the low performance on sustainable energy and building materials indicators clusters with the bad LCC score. Legal certainty suffers from a particular situation, whereby city authorities are in conflict with the higher administration over the excessively low building densities and other sustainability-related aspects.

\subsubsection{Process aspects}

The city authorities have a clear plan and target audience for the allotment and are trying to convince all other stakeholders of their accountable intentions. Thereby a remarkable coalition has emerged between the residents of the existing neighbourhood and the city authorities, for both parties aim for a drastically limited number of new dwellings in the area. At the same time, local inhabitants challenge the city over other sustainability factors. Particular concerns are the congestion problems of the N26, problems of water drainage that may affect the whole area and the sacrifice of valuable woodland for the new 'park road'.

The local politicians not only struggle with the higher administration for realizing their plans but are also criticized by the communal planning department. As a conclusion, the process could be characterized as a political manoeuvre rather than as a balanced project for integrated sustainable development.

On the other hand, contestation has obliged local politicians to start to reconsider at least some of the premises for the project. Within this ongoing controversy, a 'research proposal' has been developed and introduced to the public at a neighbourhood meeting, December 2009. This alternative development scenario is briefly discussed below in section 5.5. 
Spreeuwenhoek, Mechelen Voorlopige score: 45 / 100

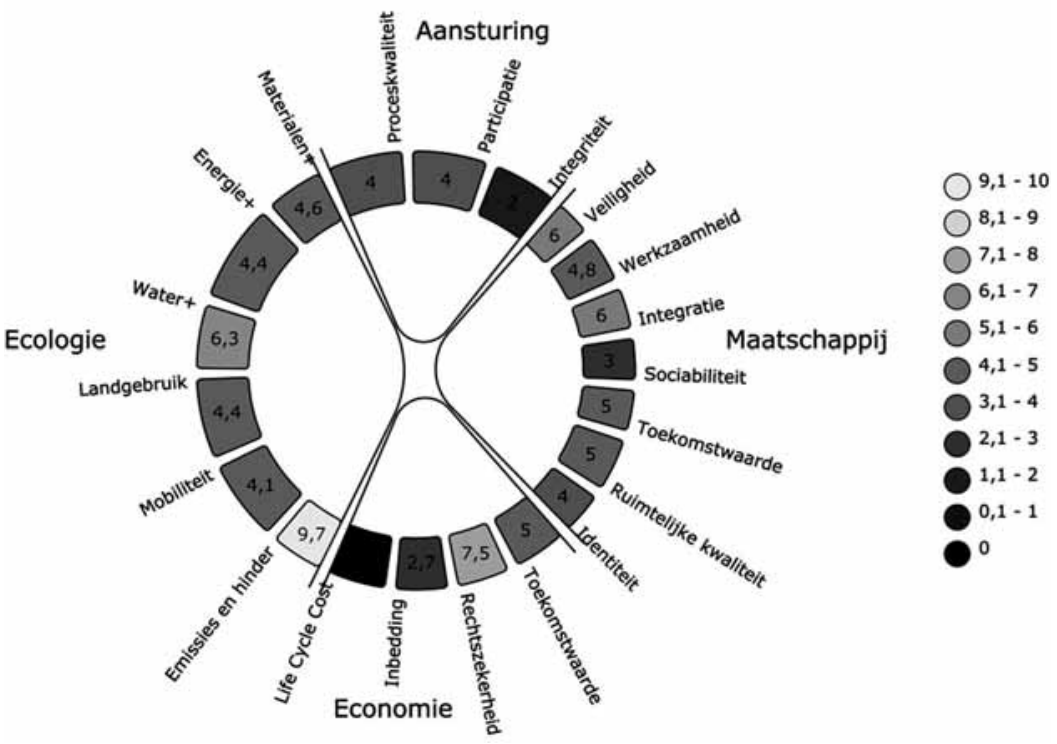

Figure 9: Radar diagram for Spreeuwenhoek peri-urban infill project (English terminology corresponding to the indicator names can be found in Fig. 3).

\subsubsection{Overall result and radar diagram}

This project cannot be judged as being sustainable from many points of view. Nevertheless, the town authorities claim a 'green' development. This turns the integrity score into one of the worst performances. The results are visualized in the radar diagram of Fig. 9.

\subsubsection{Exclusion criteria}

The threshold for newbuild energy consumption was not reached and so the label 'sustainable' cannot be assigned.

\subsection{An alternative development scheme for Spreeuwenhoek}

The aim of proposing an alternative development scenario was to feed the ongoing debate with new inputs, thereby proving that even a market-conform project could realize far better sustainability scores in all domains.

The main features of the alternative scheme (Fig. 10) are as follows:

- It starts from an infill and regeneration project within the existing neighbourhood and proposes a gradual and phased development of the Greenfield areas as the needs emerge. The services of the existing core are rehabilitated and extended to create a renewed 'neighbourhood heart';

- Greenfield construction occurs within dense urban 'fingers', so as to preserve as much valuable green space as possible. In this way, a total of 900 new dwellings can be constructed, while occupying a limited fraction of the open land;

- An existing industrial plant along the N26 is relocated and the vacant site is provided with a new urban square, housing and an access road to the eastern sector of the development; 


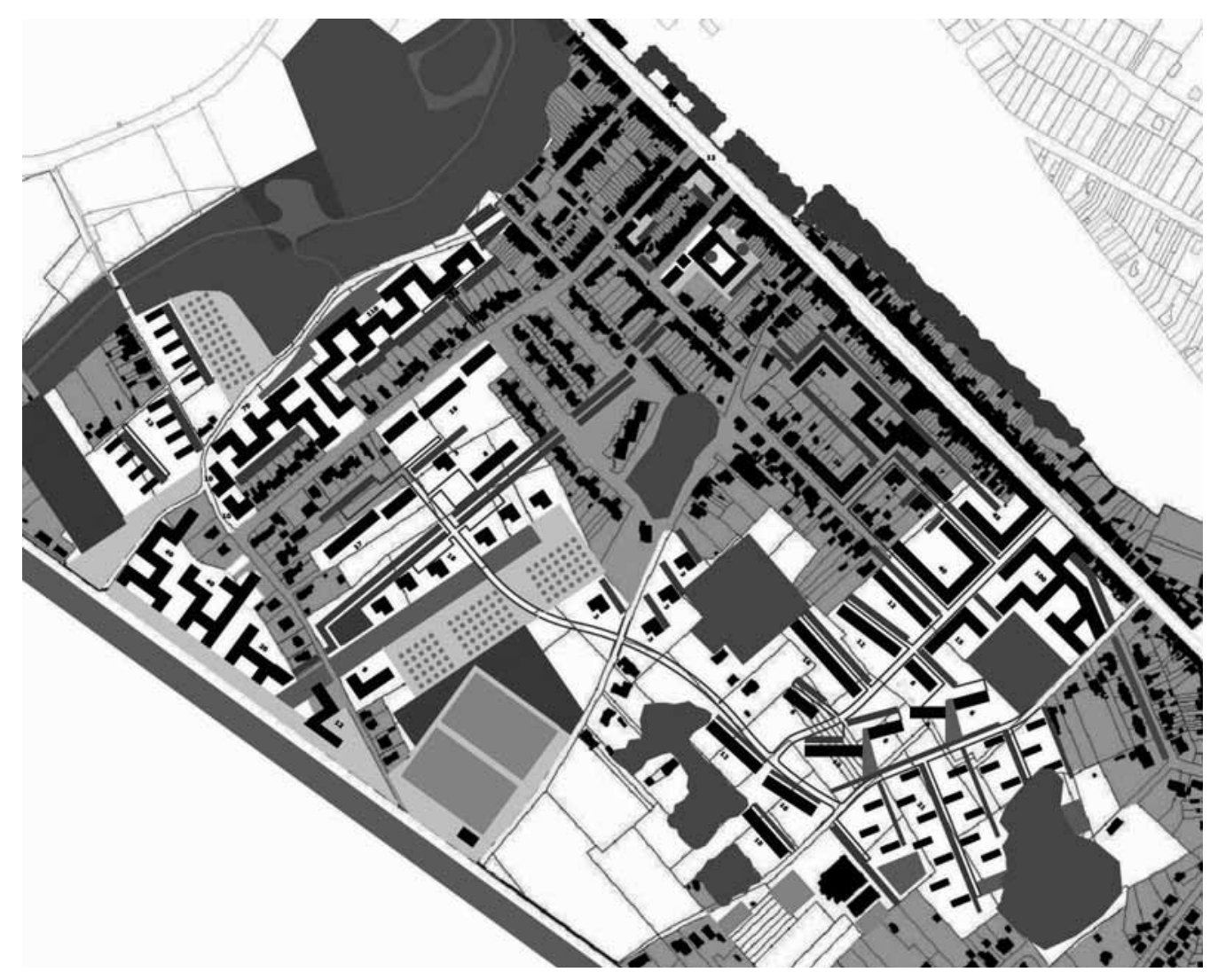

Figure 10: Alternative development, maximum scenario ( 900 additional dwellings). Phasing starts with renewal and infill of existing neighbourhood (shaded plots). A limited fraction of the existing open space is built up, even in the maximum scenario. Maximum building height is four floors (ground floor included) in denser urban clusters. A green-blue network is created starting from the existing woodlands.

- A green-blue network with provisions for walking and biking is installed. Existing woodlands and open spaces are taken as a starting point. It also provides for adequate water buffering;

- New buildings are erected with 'best available technology' (BAT) in terms of sustainable building materials, and according to a low-energy norm of $60 \mathrm{kWh} / \mathrm{m}^{2}$,year expressed as total fossil fuel consumption (heating, cooling, ventilation, lighting and appliances included).

\subsubsection{Overall result and radar diagram}

The alternative development can increase its sustainability score from the original 45 to $75 \%$. The most drastic changes occur at the scale of the urban concept and form, while environmental techniques are applied in a largely market-conform way. This proves again, as for the Cadix development, that the initial options taken at the very early planning stage (urban form and programme, overall energy concept and water cycle) create a fundamental difference. The results are represented in the radar diagram of Fig. 11. 
Spreeuwenhoek: Alternatief Voorlopige score: 75 / 100

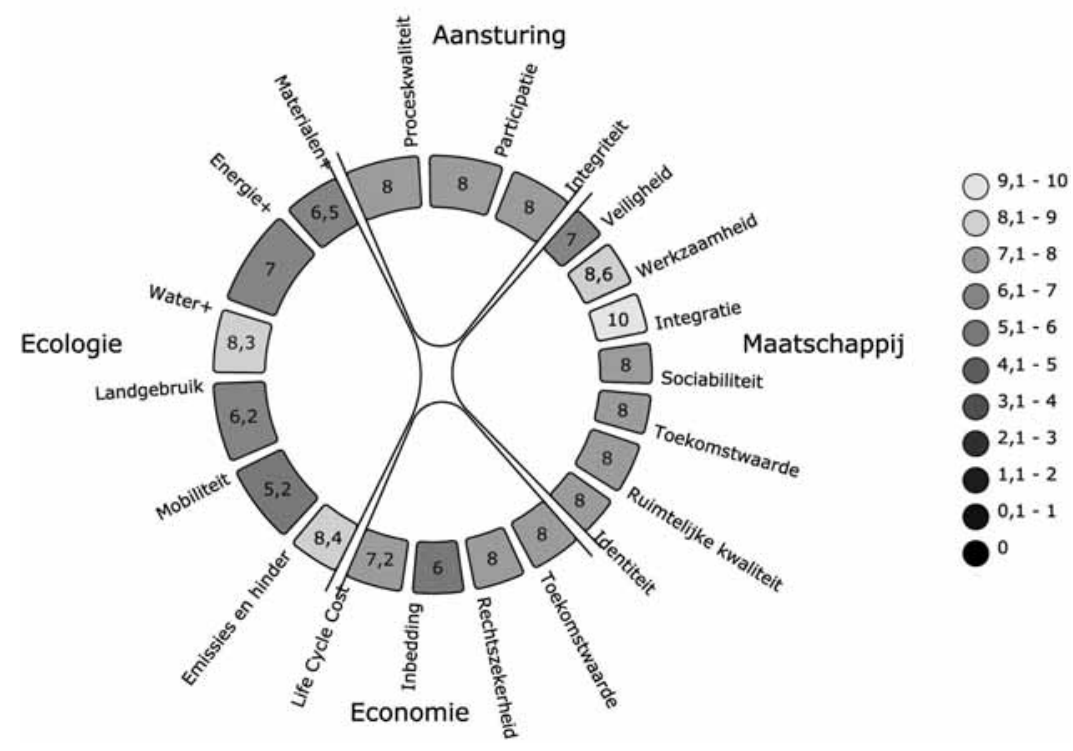

Figure 11: Radar diagram for Spreeuwenhoek, alternative infill project (English terminology corresponding to the indicator names can be found in Fig. 3).

\section{CONCLUSIONS}

The compass for evaluating sustainable urban development at the neighbourhood scale presented in this paper has set out to adopt an alternative approach to sustainable performance evaluation, as compared to instruments that adhere to a strictly quantitative setup. So an important challenge was to accommodate for qualitative judgements in a structured but non-mechanistic way.

Starting from Herman Dooyeweerd's multimodal theory, a methodology was set up to accommodate for the intended quantitative-qualitative evaluation. Aspects of different character should receive an appropriate address, although this is not always possible by means of a determinative, quantitative idiom. This should however not be considered as a problem, but rather as an incentive to use the correct frame of reference for every particular issue of integrated sustainable development. In terms of modal aspects, the assessment should thereby continue until the ethical engagements that form the basis of true sustainability are reached.

After summarizing some pragmatic starting points for the set up of the instrument, its composition is explained. The assessment uses a hierarchical indicator set with four categories and 20 main indicators, each of which may consist of up to four sub-indicators. These are rated and weighted into an overall score. The assessment is completed with a set of performance thresholds regarding particular indicators, and a full argumentation of the evaluation process. The latter can, among others, accommodate for contextual interventions, such as changing the weight factors for a particular project context. A new type of radar diagram is proposed to provide the concerned stakeholders with a userfriendly visualization of overall performance.

The case studies confirm the commonly accepted observation that the decisions with the highest sustainability impact come at the early planning stages. With appropriate concepts of urban programme and process management, urban morphology, and well-chosen overall energy and water 
management strategies, sustainability comes more naturally. It is in any case far more effective than 'greening up' a project at the level of single buildings or with the help of isolated attributes that must give a sense of perceived overall sustainability. Methodological support to project managers and stakeholders from the outset may well help to improve typical current practices.

The case studies also indicate that, even if data uncertainties prevent to construct a clear image of sustainable functioning, it is still possible to obtain a useful quick scan of a development project. In this case the evaluation delivers a concise SWOT-analysis. In particular, a lack of data may in itself reflect a weakness of the sustainability targets and so provide indications for improvement. The same holds for detecting misleading sustainability claims.

And finally, qualitative judgements can be made more robust if the instrument is used to compare projects or development scenarios with each other. This was illustrated with an alternative development scenario for one of the case studies.

In terms of future work, more research is needed to gain additional insight into the life cycle impact of entire urban fragments and systems. Methods need to be found to deal with the corresponding problems of data quantity, quality and uncertainty in particular. An expert panel could further evaluate and weight the sub-indicators, while new and more LCA-data could support more informed calibrations of the indicators and sub-indicators. Some qualitative indicators could be more structurally assessed by an explicit enumeration and weighting of the different aspects to be judged.

In case of real-world application, the instrument will have to be used by an independent assessor, however working in close collaboration with concerned actors and stakeholders for the sake of optimum transparency. This coincides with an approach of reflexive learning and governance.

\section{REFERENCES}

[1] UNFPA, State of World Population 2011, UNFPA: New York, 2011.

[2] Blum, A., HQE'R - Research and demonstration for assessing sustainable neighbourhood development (Chapter 20). Sustainable Urban Development Volume 2: The Environmental Assessment Methods, eds M. Deakin, G. Mitchell, P. Nijkamp \& R. Vreeker, Routledge: London and New York, pp. 412-428, 2007.

[3] Simmons, C., Ecological Footprint Analysis: a useful method for exploring the interaction between lifestyles and the built environment (Chapter 11). Sustainable Urban Development Volume 2: The Environmental Assessment Methods, eds M. Deakin, G. Mitchell, P. Nijkamp \& R. Vreeker, Routledge: London and New York, pp. 223-235, 2007.

[4] Stremke, S. \& Koh, J., Ecological concepts and strategies with relevance to energy-conscious spatial planning and design. Environment and Planning B: Planning and Design, 37(3), pp. 518-532, 2010. doi: http://dx.doi.org/10.1068/b35076

[5] van den Dobbelsteen, A., Broersma, S. \& Stremke, S., Energy Potential Mapping for Energy-Producing Neighborhoods. International Journal of Sustainable Building Technology and Urban Development, 2(2), pp. 170-176, 2011. doi: http://dx.doi.org/10.5390/ SUSB.2011.2.2.170

[6] Salat, S., Energy loads, CO2 emissions and building stocks: morphologies, typologies, energy systems and behaviour. Building Research \& Information, 37(5), pp. 598-609, 2009. doi: http://dx.doi.org/10.1080/09613210903162126

[7] Nijkamp, P., The role of evaluation in supporting a human sustainable development: a cosmonomic perspective (Chapter 5). Sustainable Urban Development Volume 2: The Environmental Assessment Methods, eds M. Deakin, G. Mitchell, P. Nijkamp \& R. Vreeker, Routledge: London and New York, pp. 94-109, 2007. 
[8] Lombardi, P. \& Brandon, P., The Multimodal System Approach to Sustainability Planning Evaluation (Chapter 3). Sustainable Urban Development Volume 2: The Environmental Assessment Methods, eds M. Deakin, G. Mitchell, P. Nijkamp \& R. Vreeker, Routledge: London and New York, pp. 47-64, 2007.

[9] Congress for the New Urbanism, Natural Resources Defense Council, U.S. Green Building Council, LEED 2009 for Neighborhood Development Rating System, USGBC, www.usgbc. org/DisplayPage.aspx?CMSPageID $=148$

[10] BRE, BREEAM Communities SD5065B Technical Guidance Manual, BRE Global Ltd: Watford, 2009.

[11] LEED Committees; U.S. Green Building Council. www.usgbc.org/DisplayPage. aspx?CMSPageID $=1750$.

[12] Humbert, S., Abeck, H., Bali, N. \& Horvath, A., Leadership in Energy and Environmental Design (LEED): A critical evaluation by LCA and recommendations for improvement. The International Journal of Life Cycle Assessment, 12(1), pp. 46-57, 2007.

[13] Congress for the New Urbanism, Natural Resources Defense Council \& U.S. Green Building Council, LEED 2009 for Neighborhood Development Rating System (Updated November 2011), U.S. Green Building Council: Washington DC, 2011.

[14] De Troyer, F., Synthesenota BREEAM: Duurzaamheid meten. Presentation, Core Foundation Group, Belgian Sustainable Building Council, 20 April 2009.

[15] IVAM (2005), DuurzaamheidsProfiel van een Locatie (DPL), www.ivam.uva.nl

[16] Voss, J-P., Bauknecht, D. \& Kemp, R. (eds), Reflexive Governance for Sustainable Development, Edward Elgar: Cheltenham, 2006.

[17] Bauler, T., Indicators for Sustainable Development: A Discussion of their Usability, Ph.D dissertation, Universite Libre de Bruxelles: Brussels, 2007.

[18] Hunt, D., Lombardi, D., Rogers, C. \& Jefferson, I., Application of sustainability indicators in decision-making processes for urban regeneration projects. Engineering Sustainability 161, Issue ESI/Proceedings of the Institution of Civil Engineers, pp. 77-91, 2008.

[19] Deakin, M., Mitchell, G., Nijkamp, P. \& Vreeker, R., Introduction. Sustainable Urban Development Volume 2: The Environmental Assessment Methods, eds M. Deakin, G. Mitchell, P. Nijkamp \& R. Vreeker, Routledge: London and New York, pp. 1-18, 2007.

[20] Jarzombek, M., Molecules, Money and Design: The Question of Sustainability's Role in Architectural Academe. Thresholds, 18, pp. 32-38, 1999.

[21] Guy, S. \& Farmer, G., Reinterpreting Sustainable Architecture: The Place of Technology. Journal of Architectural Education, 54(3), pp. 140-148, 2001. doi: http://dx.doi.org/10.1162/ 10464880152632451

[22] Guy, S. \& Moore, S., Sustainable Architecture and the Pluralist Imagination. Journal of Architectural Education, 60(4), pp. 15-23, 2007. doi: http://dx.doi.org/10.1111/j.1531$\underline{314 X .2007 .00104 . x}$

[23] Moe, K., Compelling Yet Unreliable Theories of Sustainability. Journal of Architectural Education, 60(4), pp. 24-30, 2007. doi: http://dx.doi.org/10.1111/j.1531-314X.2007.00105.x

[24] Pyla, P., Counter-Histories of Sustainability. 18, pp. 14-17, 2008.

[25] Borsboom, D., Mellenbergh, G. \& van Heerden, J., The Concept of Validity. Psychological Review, 111(4), pp. 1061-1071, 2004. doi: http://dx.doi.org/10.1037/0033-295X.111.4.1061

[26] Vandevyvere, H., Strategieen voor een verhoogde implementatie van duurzaam bouwen in Vlaanderen. Toepassing op het schaalniveau van het stadsfragment/ Strategies Towards Increased Sustainable Building in Flanders. Application on the Scale of the Urban Fragment, Ph.D dissertation, K.U.Leuven: Leuven, 2010. 
[27] de Raadt, J.D.R., Faith and the Normative Foundation of Systems Science. Systems Practice, 10(1), pp. 13-35, 1997. doi: http://dx.doi.org/10.1007/BF02557849

[28] Basden, A., The critical theory of Herman Dooyeweerd? Journal of Information Technology, 17(4), pp. 257-269, 2002. doi: http://dx.doi.org/10.1080/0268396022000017770

[29] Lombardi, P. \& Basden, A., Environmental Sustainability and Information Systems: The Similarity. Systems Practice, 10(4), pp. 473-489, 1997. doi: http://dx.doi.org/10.1007/BF02557893

[30] Lombardi, P. \& Brandon, P., Toward a multi-modal framework for evaluating the built environment quality in sustainability planning (s.n.). Evaluation of the Built Environment for Sustainability, eds P. Brandon, P. Lombardi \& V. Bentivegna, E\&FN Spon: London, pp. 7-24, 1997.

[31] Brandon, P. \& Lombardi, P., Evaluating Sustainable Development in the Built Environment, Wiley-Blackwell: Oxford and Ames, 2011.

[32] Dooyeweerd, H., A New Critique of Theoretical Thought, Vol. 1: The necessary presuppositions of philosophy, H.J. Paris/ The Presbyterian and Reformed Publisher Company: Amsterdam, 1953.

[33] Dooyeweerd, H., A New Critique of Theoretical Thought, Vol. 2: The general theory of the modal spheres, H.J. Paris/ The Presbyterian and Reformed Publisher Company: Amsterdam, 1955.

[34] Vandevyvere, H., From scoring to orienting: the development of a compass for evaluating sustainable urban development at the neighbourhood scale. Proc. of the 5th Int. Conf. On Sustainable Development and Planning, eds C.A. Brebbia \& E. Beriatos, WIT Press: Ashurst, pp. 153-164, 2011.

[35] WCED \& Brundtland, G.H., Our Common Future: Report of the World Commission on Environment and Development, Oxford University Press: Oxford, 1987.

[36] Basden, A., The Dooyeweerd Pages, http://www.dooy.salford.ac.uk/

[37] Rotmans, J., Methods for integrated assessment: the challenges and opportunities ahead. Environmental Model Assessment, 3(2), pp. 155-179, 1998. doi: http://dx.doi.org/10.1023/ A:1019019024003

[38] evr-Architecten - SumResearch - Daidalos Peutz, Duurzaamheidsmeter Stad Gent, Instrument voor duurzaamheid en kwaliteit in stadsontwikkelingsprojecten, handleiding, Versie 3.0, 17 december 2008.

[39] Stad Stockholms/GlashusEtt, Hammarby Sjostad - a unique environmental project in Stockholm, GlashusEtt: Stockholm, 2007.

[40] ISO, International Standard ISO 14031: Environmental management - Environmental performance evaluation - Guidelines, ISO: Geneva, 1999.

[41] Trias Energetica, http://www.triasenergetica.com/home.html

[42] AG Stadsplanning \& AG Vespa, Verkoop onder Voorwaarden, Eilandje-Cadix C2-D2, 2009. 